\title{
Early Lung Function Abnormalities in Acromegaly
}

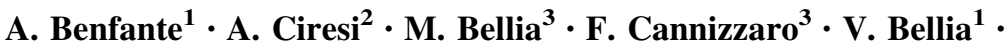 \\ C. Giordano ${ }^{2} \cdot$ N. Scichilone ${ }^{1}$
}

Received: 10 December 2014/ Accepted: 4 March 2015

(C) Springer Science+Business Media New York 2015

\begin{abstract}
Background Acromegaly is an insidious disorder caused by a pituitary growth hormone $(\mathrm{GH})$-secreting adenoma resulting in high circulating levels of $\mathrm{GH}$ and insulin-like growth factor I (IGF-I). Respiratory disorders are common complications in acromegaly, and can severely impact on quality of life, eventually affecting mortality.

Objectives The present study aimed to explore structural and functional lung alterations of acromegalic subjects.

Methods We enrolled 10 consecutive patients (M/F: 5/5) affected by acromegaly. In all patients, magnetic resonance imaging (MRI) revealed the presence of pituitary tumor. All patients underwent clinical, lung functional, biological, and radiological assessments. Ten healthy age-matched subjects also served as controls.

Results No statistically significant differences in lung function were detected between acromegalic and healthy subjects ( $p \geq 0.05$ for all analyses). However, the diffusing capacity for CO (TLCO) was significantly lower in the acromegalic group than in healthy subjects (TLCO\% predicted: $78.1 \pm 16$ vs. $90 \pm 6 \%$, respectively, $p=0.04$;
\end{abstract}

Dr. Benfante and Ciresi equally contributed to the preparation of the manuscript.

N. Scichilone

nicola.scichilone@unipa.it

1 Dipartimento Biomedico di Medicina Interna e Specialistica, Sezione di Pneumologia, Università degli Studi di Palermo, via Trabucco 180, 90146 Palermo, Italy

2 Dipartimento Biomedico di Medicina Interna e Specialistica, Sezione di Endocrinologia, Università degli Studi di Palermo, Palermo, Italy

3 Dipartimento di Biotecnologie e Medicina Legale, Sezione di Scienze Radiologiche, University of Palermo, Palermo, Italy
KCO $\%$ predicted: $77 \pm 16$ vs. $93 \pm 5 \%, p=0.02$, respectively). None of the lung function parameters correlated with duration of the disease, or with inflammatory marker of the airways. In acromegalics, biological (exhaled NO concentrations) and imaging (total lung volume, TLV, and mean lung density, MLD) evaluations were within normal values. The TLV measured by HRCT was $3540 \pm 1555 \mathrm{ml}$ in acromegalics, and the MLD was $-711 \pm 73 \mathrm{HU}$. None of the lung functional, radiological, and biological findings correlated with GH or IGF-I levels, and no correlation was found with duration of disease.

Conclusions In the current study, lung function evaluation allowed to detect early involvement of lung parenchyma, as assessed by TLCO and KCO, even in the absence of parenchymal density alterations of the lung by HRCT. These findings suggest to routinely include the carbon monoxide diffusing capacity in the lung function assessment for an early intervention in acromegaly.

Keywords Imaging - Lung function · Acromegaly · Diffusing capacity

$\begin{array}{ll}\text { Abbreviations } \\ \text { COPD } & \text { Chronic obstructive pulmonary disease } \\ \text { FENO } & \text { Fractional exhaled nitric oxide } \\ \text { FEV }_{1} & \text { Forced expiratory volume in the 1st second } \\ \text { FVC } & \text { Forced vital capacity } \\ \text { GH } & \text { Growth hormone } \\ \text { HRCT } & \text { High-resolution computed tomography } \\ \text { HU } & \text { Hounsfield unit } \\ \text { IGF-I } & \text { Insulin-like growth factor I } \\ \text { KCO } & \text { Carbon monoxide transfer coefficient } \\ \text { LAV } & \text { Low attenuation volume } \\ \text { MRI } & \text { Magnetic resonance imaging } \\ \text { OGTT } & \text { Oral glucose tolerance test }\end{array}$


SAS Sleep apnea syndrome

TLC Total lung capacity

TLCO Transfer factor of the lung for carbon monoxide
In the attempt to establish whether, and to what extent, the lung is involved in acromegaly, the present study aimed to explore structural and functional lung alterations of acromegalic subjects. To this aim, clinical, radiological, biological, and lung functional assessments were performed.

\section{Material and Methods}

Acromegaly is an insidious disorder caused by a pituitary growth hormone $(\mathrm{GH})$-secreting adenoma resulting in high circulating levels of $\mathrm{GH}$ and insulin-like growth factor (IGF-I) [1]. During the natural course of acromegaly, the elevated GH and IGF-I levels lead to a wide range of cardiovascular, respiratory, endocrine, and metabolic comorbidities that contribute to significantly enhanced mortality. The goals of therapy in patients with acromegaly are the elimination of morbidities associated with the disease and normalization of the increased mortality. Surgery, radiation, and medical treatments are available for lowering GH and IGF-I hypersecretion, controlling pituitary tumor mass effects, and improving morbidity, although no single therapy is comprehensively successful in controlling the disease and its clinical manifestations, and often multimodal therapies are required for disease control through suppression of $\mathrm{GH}$ hypersecretion, reduction of IGF-I levels, and control of tumor growth [2, 3]. Comorbidities should be evaluated and treated during acromegaly within the clinical context, and the reduction in GH and IGF-I levels is a valuable and accurate marker for improvement of the comorbidity associated with acromegaly [4].

Respiratory disorders are common complications in acromegaly, and the mortality rates from respiratory causes are threefold more common than in the general population [5]. Deformities of facial bones, edema, and hypertrophy of the mucosae and pharyngeal and laryngeal cartilages, enlargement of the tongue and inspiratory collapse of the hypopharinx, may contribute to respiratory alterations. Generalized soft-tissue thickening is a well-known feature of acromegaly and is related to glycosaminoglycan deposition, as well as to increased collagen production by connective tissue and tissue edema. The sleep apnea syndrome (SAS) is the most common respiratory alteration in acromegalic individuals, affecting 60-70 \% of acromegalic patients and may present as obstructive, central, or mixed [6]. In addition, acromegalic pneumomegaly is frequently observed and, as suggested by lung functional studies, it might be due to an increased number, rather than volume, of the alveoli, although data are controversial [7, 8]. Despite the increase in lung size, however, the single-breath carbon monoxide transfer coefficient (KCO) appears to be lower than expected, thus implying parenchymal alterations.

\section{Subjects}

For the purpose of the study, we enrolled ten consecutive patients (M/F: 5/5) affected by acromegaly visiting the Endocrinology Section of the University of Palermo in 2011. Smoker patients or those with already known respiratory diseases were excluded from this study. Ten healthy age-matched subjects served as controls. They had never experienced respiratory symptoms consistent with the diagnosis of chronic obstructive pulmonary disease (COPD) or other lung disease, nor had they ever been diagnosed with COPD or another lung disease by a physician, and none of them was on any respiratory medication regimen. Out of the ten patients included in the study, three were newly diagnosed patients, not receiving any acromegalic treatment, three were treated with first-line octreotide-long acting release (20-30 mg every 28 days), 1 with lanreotide autogel (90 mg every 28 days), 2 with pegvisomant (10-15 mg/daily), and one patient had recently received pituitary surgery. In all patients, MRI (magnetic resonance imaging) scan revealed the presence of a pituitary tumor. The mean duration of disease was established by patient interview, patients' pictures, and onset of osteoarticular symptoms.

Based on the nadir GH after oral glucose tolerance test (OGTT) and IGF-1 levels, patients were divided into those with controlled $(N o=5)$ and those with uncontrolled $(N o=5)$ acromegaly. Cut-off level for controlled subjects was $1 \mu \mathrm{g} / \mathrm{l}$ for random $\mathrm{GH}$ and $0.4 \mu \mathrm{g} / \mathrm{l}$ after OGTT, together with IGF-1 in the age-adjusted normal range, with the exception of patients under pegvisomant treatment, in whom only IGF-1 levels were considered as parameter of activity of disease [9]. At the time of hospitalization, all patients signed an informed consent for the scientific use of their data. The study was approved by the Institutional Review Board of the Faculty of Medicine, University of Palermo, given that the identity of the participants remained anonymous during database analysis.

\section{Study Design}

The study included a total of three visits. All enrolled patients underwent an initial assessment (Visit 1) in which 
body mass index, and systolic and diastolic blood pressures were measured in the morning. After an overnight fast, mean fasting plasma GH (at least three blood samples at 30-min intervals) and IGF-I levels were measured. OGTT was performed in all patients by measuring plasma blood glucose, insulin levels, and GH every 30 min for $2 \mathrm{~h}$ after $75 \mathrm{~g}$ oral glucose load. The pulmonary evaluation was conducted on two days. The first day (Visit 2) included clinical, biological, and lung function assessments. On a separate occasion (Visit 3), lung imaging procedures were carried out. All patients were in stable conditions on study days.

\section{Clinical and Functional Assessments}

Functional assessment included measures of static and dynamic lung volumes, as well as single-breath diffusing capacity for $\mathrm{CO}$, which were performed using a fully computerized water-sealed Stead-Wells spirometer (Baires System; Biomedin; Padua, Italy). The transfer factor of the lung for $\mathrm{CO}$ (TLCO) and the $\mathrm{KCO}$ was measured to evaluate the extent of lung parenchymal destruction. At least two determinations of TLCO that were within $5 \%$ of each other were obtained, and the highest value was retained for analysis. Measurements were made in accordance with the European Thoracic Society standardisation document on lung volume measurements [10]. $\mathrm{FEV}_{1} \%$ (forced expiratory volume in the 1st second) predicted and FVC\% (forced vital capacity) predicted, as well as TLC\% (total lung capacity) predicted, TLCO\% predicted, and $\mathrm{KCO} \%$ predicted were calculated and used for the analysis.

\section{Biological Assessment}

Exhaled nitric oxide (FENO) was measured with a standardized single-breath method using the electrochemical analyzer (Hypair FENO®, Medisoft), which was calibrated daily. The measurement procedure was consistent with guidelines published by the American Thoracic Society/European Respiratory Society [11]. Subjects were in sitting position during the entire procedure. Each individual was asked to take a deep inspiration from room air and, immediately after, to forcefully exhale through the mouthpiece that was connected to the on-line analyzer. To determine if subjects maintained a constant flow-rate during exhalation, a continuous monitoring of expiratory flow-rate by graphic display on the monitor screen was used. All samples were acquired in the morning between 11:00 and 12:00. FENO was obtained as the mean of three acceptable measurements at the airflow rate of $50 \mathrm{ml} / \mathrm{s}$.

\section{Imaging Assessment}

Each subject underwent high-resolution computerized tomography (HRCT), which was performed by spiral computed tomography (multidetector 64 channels equipment, Philips Medical System, Cleveland, $\mathrm{OH}$ ), with a setting of $120 \mathrm{kVp}, 200 \mathrm{mAs}$, a 0.9-mm slice thickness, a rotation time $0.5 \mathrm{~s}$, and a reconstruction interval of $0.45 \mathrm{~mm}$, pitch 0.923 , during a single breath and moved caudally. Images were reconstructed at a window level of -600 Hounsfield units (HU) and a window width of $1600 \mathrm{HU}$.

Two radiologists (MB and FC) evaluated the CT scans independently, excluding any radiological abnormality of the lung parenchyma. Total lung volume and parenchymal density on the HRCT scans as an estimate of parenchymal damage were measured at full inspiration. Total lung volume was calculated and expressed in $\mathrm{cm}^{3}$. Parenchymal density was expressed by lung attenuation parameters, such as mean lung density at FRC, functional residual capacity (Mean $\mathrm{HU}_{\text {exp }}$ ) and at TLC, total lung capacity (Mean $\mathrm{HU}_{\text {insp); }}$ ) in addition, the percent of the lung with a low attenuation volume at TLC (i.e., below -950 HU, LAV) was measured as an estimate of the degree of emphysema.

\section{Statistical Analysis}

Statistical analysis was performed using Statview ${ }^{\circledR} 5.0$ (SAS Institute Inc., Cary, NC, USA). Univariate analysis and correlation analysis were performed. Data are expressed as mean \pm SD. Significance level was set at $p \leq 0.05$.

\section{Results}

The clinical characteristics and endocrine status of the study subjects are presented in Table 1. Duration of the disease was $5.5 \pm 3.9$ yrs (range: 1-11 years). $\mathrm{FEV}_{1} \%$ predicted was $115 \pm 21 \%$ (mean $\pm \mathrm{SD}$, range: 89-156 \%), FVC \% predicted was $120 \pm 21 \%$ (range: 91-162 \%), $\mathrm{FEV}_{1} / \mathrm{FVC}$ was $0.79 \pm 0.5$ (range: 0.73-0.89), and TLC predicted was $110 \pm 16 \%$ (range: 93-144\%); in addition, TLCO $\%$ predicted was $78.1 \pm 16 \%$ (range: $58-111 \%$ ) and $\mathrm{KCO} \%$ predicted equal to $77 \pm 16 \%$ (range: 56-92 \%). Finally, FeNO was $12 \pm 8$ ppb (range: 4-30 ppb). Healthy controls were matched by gender (5 males and 5 females for each group), age (44 \pm 13 vs. $52 \pm 10$ years, $p=0.17)$, and height $(168 \pm 9$ vs. $169 \pm 10 \mathrm{~cm}, p=0.85)$. In healthy controls, $\mathrm{FEV}_{1} \%$ predicted was $110 \pm 7 \%$ (mean $\pm \mathrm{SD}$, range: $99-122 \%$ ), FVC \% predicted was $112 \pm 7 \%$ (range: 100-123\%), $\mathrm{FEV}_{1} / \mathrm{FVC}$ was $0.82 \pm 1.3$ (range: $0.80-0.84$ ), and TLC predicted was $105 \pm 10 \%$ (range: $90-117 \%$ ). TLCO $\%$ 
Table 1 Demographic and clinical characteristics of acromegalic subjects

\begin{tabular}{|c|c|c|c|c|c|c|c|c|c|c|}
\hline $\begin{array}{l}\text { Patient } \\
\text { No. }\end{array}$ & Gender & Age & Smoking & BMI & $\begin{array}{l}\text { Duration } \\
\text { of disease } \\
\text { (yearr) }\end{array}$ & $\begin{array}{l}\text { GH mean } \\
\text { baseline } \\
(\mu \mathrm{g} / \mathrm{L})\end{array}$ & $\begin{array}{l}\text { GH after } \\
\text { oral glucose } \\
\text { load }(\mu \mathrm{g} / \mathrm{L})\end{array}$ & $\begin{array}{l}\text { Mean } \\
\text { IGF-1 } \\
(\mu \mathrm{g} / \mathrm{L})\end{array}$ & $\begin{array}{l}\text { Concomitant } \\
\text { Diseases }\end{array}$ & GH hypersecretion treatment \\
\hline 1 & M & 65 & $\mathrm{~F}$ & 31.1 & 10 & 6.8 & 3.7 & 756 & $\begin{array}{l}\text { Hypertension, } \\
\text { dyslipidemia }\end{array}$ & $\begin{array}{l}\text { Octreotide LAR } \\
20 \mathrm{mg} / \mathrm{monthly}\end{array}$ \\
\hline 2 & M & 46 & $\mathrm{~N}$ & 26.7 & 1 & 8 & \#\#\# & 848 & Hypertension & None (newly diagnosed) \\
\hline 3 & $\mathrm{~F}$ & 53 & $\mathrm{~N}$ & 37.2 & 1 & 3 & 1 & 600 & Hypertension & None (newly diagnosed) \\
\hline 4 & M & 57 & $\mathrm{~N}$ & 34.6 & 5 & 3.28 & \#\#\# & 231 & $\begin{array}{l}\text { Hypertension, } \\
\text { dyslipidemia }\end{array}$ & Post-surgery \\
\hline 5 & $\mathrm{~F}$ & 50 & $\mathrm{~N}$ & 26 & 4 & \#\#\# & \#\#\# & 722 & Hypertension & $\begin{array}{l}\text { Octreotide } 30 \mathrm{mg} / \mathrm{monthly}, \\
\text { pegvisomant } 15 \mathrm{mg} / \text { daily, } \\
\text { cabergoline } 1 \mathrm{mg} / \text { weekly }\end{array}$ \\
\hline 6 & $\mathrm{~F}$ & 39 & $\mathrm{~N}$ & 29.4 & 6 & 1.24 & 0.56 & 115 & Hypothyroidism & Lanreotide $90 \mathrm{mg} / 2$ month \\
\hline 7 & M & 52 & $\mathrm{~N}$ & 24.8 & 11 & \#\#\# & \#\#\# & 137 & None & $\begin{array}{l}\text { Octreotide } 30 \mathrm{mg} / \mathrm{monthly} \text {, } \\
\text { pegvisomant } 10 \mathrm{mg} / \text { daily }\end{array}$ \\
\hline 8 & M & 41 & $\mathrm{~N}$ & 30.5 & 1 & 31 & 26 & 1049 & None & None (newly diagnosed) \\
\hline 9 & $\mathrm{~F}$ & 48 & $\mathrm{~N}$ & 39.4 & 6 & 1.6 & 0.8 & 273 & $\begin{array}{l}\text { Hypertension, } \\
\text { dyslipidemia. }\end{array}$ & Octreotide $30 \mathrm{mg} / \mathrm{monthly}$ \\
\hline 10 & $\mathrm{~F}$ & 71 & $\mathrm{~N}$ & 29 & 10 & 1.2 & 0.8 & 225 & $\begin{array}{l}\text { Hypertension, } \\
\text { dyslipidemia }\end{array}$ & Octreotide $20 \mathrm{mg} / \mathrm{monthly}$ \\
\hline
\end{tabular}

predicted and $\mathrm{KCO} \%$ predicted were $90 \pm 6 \%$ (range: 80-100\%) and $93 \pm 5 \%$ (range: $85-101 \%$ ), respectively. We did not find statistically significant differences in lung function between acromegalic and healthy subjects ( $p \geq 0.05$ for all analyses). However, TLCO was significantly lower in the acromegalic group than in healthy subjects (TLCO $\%$ predicted and $\mathrm{KCO} \%$ predicted: $p=0.04$ and $p=0.02$, respectively). Complete lung function characteristics of acromegalic and control subjects are presented in Table 2 and 3, respectively.

When we divided the patients according to the disease activity, no differences in static and dynamic lung volumes, as well as diffusing CO capacity, were detected between patients with controlled and uncontrolled acromegaly ( $p>0.05$ in all comparisons). In addition, none of the lung function parameters correlated with duration of the disease.

In acromegalic subjects, the total lung volume measured by HRCT was $3540 \pm 1555 \mathrm{ml}$, the mean lung density was $-711 \pm 73 \mathrm{HU}$, and LAV\% total was $6.6 \pm 6 \%$. None of the imaging parameters differentiated acromegalic from healthy subjects, or between active and inactive disease. However, the lung density evaluated by HRCT significantly correlated with TLCO $\%$ predicted $(r=0.70$, $p=0.03$ ).

Additional investigations were performed in acromegalic subjects with the aim to evaluate which factors can eventually influence the carbon monoxide transfer coefficient and the diffusing capacity for CO. The alternative hypothesis that pulmonary hypertension can affect the current findings was ruled out by normal values obtained with transthoracic echocardiography. In addition, nocturnal oxygen monitoring was performed to screen for nocturnal reduction in oxygen saturation. All but one subject showed during the recording time an oxygen saturation higher than $90 \%$ (mean value: $94 \%$ ).

\section{Discussion}

Acromegaly is considered a rare disease in the general population. However, its impact on morbidity and mortality, as well as on health service costs, is not trivial. Respiratory disorders are common complications in acromegaly, and can severely impact on quality of life, eventually affecting mortality. Thus, early identification of lung function impairment could contribute to proper management of the disease. In the current study, lung function evaluation allowed to detect early involvement of lung parenchyma, as assessed by TLCO and $\mathrm{KCO}$, even in the absence of parenchymal density alterations of the lung by HRCT.

Studies investigating the involvement of the respiratory system in acromegaly have primarily focused on the occurrence of obstructive sleep apnea, which is a common disorder in this disease [6]. Other lung abnormalities, such as larger lungs, were described by Siafakas and colleagues [12]. Trotman-Dickenson and colleagues [13] assessed pulmonary function and disease activity in patients with acromegaly (19 men and 16 women): large lungs occurred 


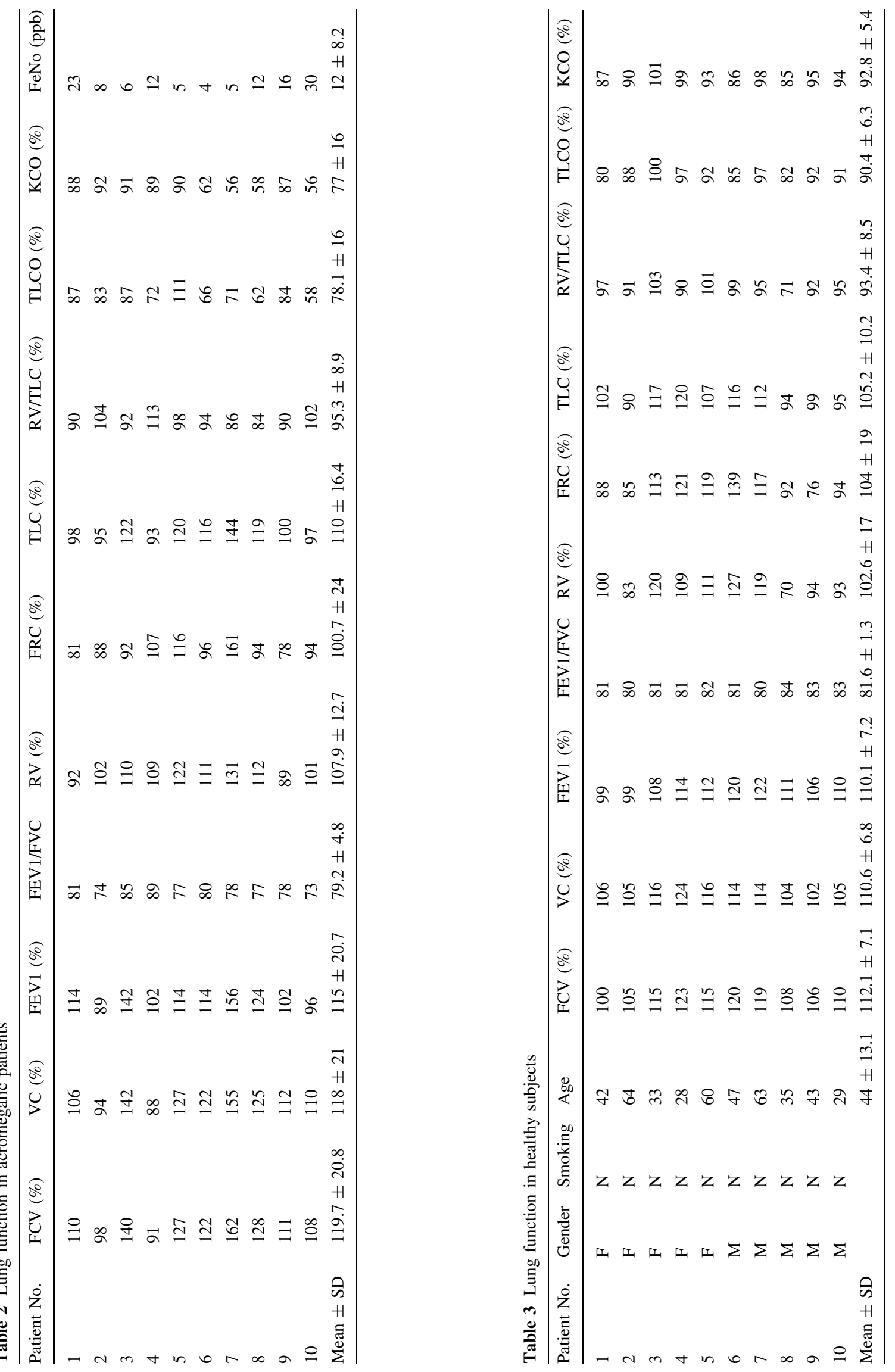


in 12 patients (34\%) and upper airflow obstruction in 17 patients $(50 \%)$. More recently, studies have focused on structural and functional abnormalities of the lung that may be linked to the acromegalic-related pathological processes. In this respect, a cross-sectional study including 20 acromegalic patients and 20 age-and height-matched control subjects was conducted with the objective to describe the abnormalities in lung structure and function [14]. The main findings in HRCT in acromegalic patients were air trapping, airway calcification, and bronchiectasis, which were observed in 60, 40, and $35 \%$ of cases, respectively. As in our study, there was no significant correlation between the levels of $\mathrm{GH}$ and insulin-like growth factor I (IGF-I) and lung function. Interestingly, the diffusing capacity for $\mathrm{CO}$ in the two studies was within the normal range, and not different from healthy subjects. These observations are in contrast with our findings. As discussed below, we reasonably excluded parenchymal causes. We believe that the discrepancy between our and other studies is only apparent, since the latter showed larger lung volumes than healthy controls, perhaps explaining normal TLCO values. This is further confirmed by the fact that our study subjects did not differ in terms of height. Other authors hypothesized that the diffusing capacity is reduced both in normal and acromegalic subjects with large lungs $[15,16]$, as extrapolated by findings of reduced values associated with increasing height in healthy children, suggesting greater recruitment of pulmonary vascular bed at the apexes in the shorter subjects.

It has been accepted that the excess of $\mathrm{GH}$ in acromegaly induces growth of the lungs. However, the mechanism by which increased lung growth occurs in acromegaly is not clear, because studies gave contradictory results. In a study on the possible mechanisms for the increased lung growth in acromegalic subjects, Brody et al. [8] found increased values for TLC, normal elastic recoil, and normal specific lung compliance. The authors found normal values for TLCO and a reduced $\mathrm{KCO}$, which suggested that the increased size of the lung in acromegaly resulted from an increase in alveolar size rather than number, resulting from an alteration of the elastic properties of the lungs. Alternative hypotheses, such as the contribution of pulmonary hypertension and the occurrence of nocturnal reductions in oxygen saturation, were reasonably excluded in the current study. Since the reduced carbon monoxide transfer coefficient and the reduced diffusing capacity cannot be justified by parenchymal density alterations of the lung by HRCT, we suggest the occurrence of an alveolar membrane damage or a microvascular damage in acromegalic subjects. Further studies are needed to test this hypothesis.

A significant correlation between duration of acromegaly and lung size was previously demonstrated [17]. It has been suggested that when duration of disease exceeds eight years, patients are very likely to develop abnormalities of lung function either primarily from the effects of acromegaly on the lung, or due to the associated cardiovascular and thoracic skeletal abnormalities. Moreover, some studies showed that a decrease in lung size occurs in patients who develop GH deficiency and thus, that normal levels of $\mathrm{GH}$ are necessary for maintaining normal lung size during adult life. De Troyer et al. [18] investigated the pulmonary function in eight patients with hypopituitarism in order to determine if the lung is affected by the generalized visceral atrophy of hypopituitarism; six patients with acromegaly and trophic hormone deficiencies were studied for comparison. The patients with hypopituitarism, including one with isolated GH deficiency, had a restrictive type of ventilatory impairment, which could not be related to neuromuscular impairment or to an abnormality of chest wall mechanics. Donnelly and colleagues [7] hypothesized that lung size in acromegaly is achieved through a process of alveolar hyperplasia rather than hypertrophy. They attributed the decrease in KCO due to an increase in the unperfused capillary bed, which is caused by the greater perfusion distances and the lower pulmonary capillary blood volume in the acromegalic lung.

In conclusion, the current findings confirm and extend previous observations in acromegaly, suggesting that the lung is largely, and perhaps invariably, involved in this disease. The lack of a comprehensive histologic evaluation of the lung from acromegalic patients does not allow to draw definite conclusions on the amount and quality of pulmonary involvement in this disease. This approach could lead to the identification of an alveolar membrane or microvascular damage, at the level of which the primary cause of the functional alterations lies. Following this primary step, the role of smoke or other lung diseases should be investigated in this population, to estimate to what extent the natural course of the disease can be affected. On this basis, we propose to routinely incorporate the carbon monoxide diffusing capacity in the lung function assessment for a proper management of the disease.

\section{Conflict of interest None.}

\section{References}

1. Melmed S (1990) Acromegaly. N Engl J Med 322:966-977

2. Frohman LA (1996) Acromegaly: what constitutes optimal therapy? J Clin Endocrinol Metab 81:443-444

3. Trainer PJ (2002) Editorial: Acromegaly-consensus, what consensus? J Clin Endocrinol Metab 87:3534-3536

4. Melmed S, Casanueva FF, Cavagnini F, Chanson P, Frohman L, Grossman A, Ho K, Kleinberg D, Lamberts S, Laws E, Lombardi G, Vance ML, Werder KV, Wass J, Giustina A (2002) 
Acromegaly treatment consensus workshop participants. Guidelines for acromegaly management. J Clin Endocrinol Metab 87(9):4054-4058

5. Murrant NJ, Gatland DJ (1990) Respiratory problems in acromegaly. J Laryngol Otol 104:52-55

6. Attal P, Chanson P (2010) Endocrine aspects of obstructive sleep apnea. J Clin Endocrinol Metab 95:483-495

7. Donnelly PM, Grunstein RR, Peat JK, Woolcock AJ, Bye PT (1995) Large lungs and growth hormone: an increased alveolar number? Eur Resp J 8(6):938-947

8. Brody JS, Fisher AB, Gocmen A, DuBois AB (1970) Acromegalic pneumonomegaly: lung growth in the adult. J Clin Invest 49(6): 1051-1060

9. Giustina A, Chanson P, Bronstein MD, Klibanski A, Lamberts S, Casanueva FF, Trainer P, Ghigo E, Ho K, Melmed S (2010) Acromegaly Consensus Group 2010. A consensus on criteria for cure of acromegaly. J Clin Endocrinol Metab 95(7):3141-3148

10. Pellegrino R, Viegi G, Brusasco V, Crapo RO, Burgos F, Casaburi R, Coates A, van der Grinten CPM, Gustafsson P, Hankinson J, Jensen R, Johnson DC, MacIntyre N, McKay R, Miller MR, Navajas D (2005) Pedersen OF and Wanger J : Interpretative strategies for lung function tests. Eur Respir J 26(5):948-968

11. American Thoracic Society; European Respiratory Society (2005) ATS/ERS Recommendations for standardized procedures for online and offline measurement of exhaled lower respiratory nitric oxide and nasal nitric oxide. Am J Respir Crit Care Med 171(8):912-930

12. Siafakas NM, Sigales J, Filaditaki B, Tsirogiannis K (1987) Small airway function in acromegaly. Bull Eur Physiopathol Respir 23(4):329-334

13. Trotman-Dickenson B, Weetman AP, Hughes JM (1991) Upper airflow obstruction and pulmonary function in acromegaly: relationship to disease activity. Q J Med 79(290):527-538

14. Camilo GB, Guimarães FS, Silva DP, Mogami R, Kasuki L, Gadelha MR, Melo PL, Lopes AJ (2013) Pulmonary function testing and chest tomography in patients with acromegaly. Multidiscip Respir Med 8:70

15. O'Brodovich HM, Mellins RB, Mansell AL (1982) Effects of growth on the diffusion constant for carbon monoxide. Am Rev Respir Dis 125:670-673

16. Burri G, Cook CD, Barrie H (1961) Studies of respiratory physiology in children: total lung diffusion, diffusing capacity of pulmonary membrane and pulmonary capillary blood volume in normal subjects from 7 to 40 years of age. J Pediatr 58(6):820-828

17. Harrison BD, Millhouse KA, Harrington M, Nabarro JD (1978) Lung function in acromegaly. Q J Med 47(188):517-532

18. De Troyer A, Desir D, Copinschi G (1980) Regression of lung size in adults with growth hormone deficiency. Q J Med 49:329-340 